\title{
Abnormal passive chloride absorption in cystic fibrosis jejunum functionally opposes the classic chloride secretory defect
}

\author{
Michael A. Russo, ${ }^{1,2}$ Christoph Högenauer, ${ }^{1,3}$ Stephen W. Coates, Jr., ${ }^{1}$ Carol A. Santa Ana, ${ }^{1}$

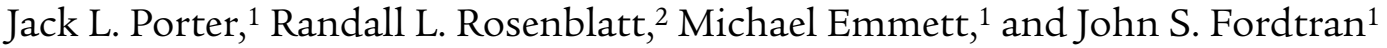 \\ ${ }^{1}$ Baylor University Medical Center, Dallas, Texas, USA \\ ${ }^{2}$ Children's Medical Center, Dallas, Texas, USA \\ ${ }^{3}$ Karl-Franzens University, Graz, Austria
}

\begin{abstract}
Due to genetic defects in apical membrane chloride channels, the cystic fibrosis (CF) intestine does not secrete chloride normally. Depressed chloride secretion leaves CF intestinal absorptive processes unopposed, which results in net fluid hyperabsorption, dehydration of intestinal contents, and a propensity to inspissated intestinal obstruction. This theory is based primarily on in vitro studies of jejunal mucosa. To determine if CF patients actually hyperabsorb fluid in vivo, we measured electrolyte and water absorption during steady-state perfusion of the jejunum. As expected, chloride secretion was abnormally low in CF, but surprisingly, there was no net hyperabsorption of sodium or water during perfusion of a balanced electrolyte solution. This suggested that fluid absorption processes are reduced in CF jejunum, and further studies revealed that this was due to a marked depression of passive chloride absorption. Although $\mathrm{Na}^{+}$-glucose cotransport was normal in the $\mathrm{CF}$ jejunum, absence of passive chloride absorption completely blocked glucose-stimulated net sodium absorption and reduced glucose-stimulated water absorption $66 \%$. This chloride absorptive abnormality acts in physiological opposition to the classic chloride secretory defect in the CF intestine. By increasing the fluidity of intraluminal contents, absence of passive chloride absorption may reduce the incidence and severity of intestinal disease in patients with CF.
\end{abstract}

J. Clin. Invest. 112:118-125 (2003). doi:10.1172/JCI200317667.

\section{Introduction}

Cystic fibrosis (CF) is caused by mutations in the $\mathrm{CF}$ transmembrane conductance regulator (CFTR) gene. CFTR functions as a chloride channel in apical or basal membranes of epithelial cells, and, in addition, it regulates the activity of other ion channels and ion transport carriers $(1,2)$. The clinical manifestations of $\mathrm{CF}$ are believed to be due primarily to defects in epithelial cell ion transport in organs such as the lung, pancreas, and intestine (3).

CF intestinal disease is believed to result from hyperabsorption of water from the intestinal lumen. It is well established that the CF intestine does not secrete chloride normally, and some (4-7), but not other (8-11), investigators have reported increased absorption of sodium and/or glucose by CF intestine. Since intestinal water movement is determined by net movement of

Received for publication December 19, 2002, and accepted in revised form April 22, 2003.

Address correspondence to: John S. Fordtran, Baylor University Medical Center, 3500 Gaston Avenue, Dallas, Texas 75246, USA. Phone: (214) 820-2672; Fax: (214) 820-4837;

E-mail: johnfo@baylorhealth.edu.

Conflict of interest: The authors have declared that no conflict of interest exists.

Nonstandard abbreviations used: cystic fibrosis (CF); CF transmembrane conductance regulator (CFTR); polyethylene glycol (PEG); potential difference (PD). solute, either decreased chloride secretion or increased sodium or glucose absorption would result in hyperabsorption of water. This, in turn, may produce dehydration and inspissation of intestinal contents, manifested clinically as meconium ileus in newborns or distal intestinal obstruction syndrome (meconium ileus equivalent) in children and adults. Most experimental data supporting the fluid hyperabsorption theory have been obtained in vitro under short-circuit conditions with jejunum of humans or mice (5-9, 11-13). This technique, however, eliminates passive ion movement in response to electrochemical gradients, which is required for net ion transport under in vivo conditions, and it does not allow measurement of net water absorption. It is not known, therefore, if the ion transport abnormalities identified in CF jejunum by in vitro studies would actually result in net hyperabsorption of electrolytes and water in vivo. Although two in vivo studies in humans confirmed reduced active chloride secretion by CF jejunum, both employed test solutions that purposely prevented normal absorptive processes in order to measure the magnitude of active chloride secretion $(14,15)$.

To further evaluate the hyperabsorption hypothesis, we measured jejunal electrolyte and water absorption in 12 adult CF patients in vivo. Although defective chloride secretion was confirmed, CF patients did not 
hyperabsorb electrolytes or water during perfusion of a physiological electrolyte solution. This indicated that fluid absorptive processes by $\mathrm{CF}$ jejunum were inhibited by some unknown mechanism. Further studies revealed that this inhibition is due to absence of passive chloride absorption. This abnormality in CF jejunum virtually eliminates glucose-stimulated sodium absorption, and by retarding jejunal water absorption it acts in physiological opposition to the classic CF chloride secretory defect.

\section{Methods}

The Institutional Review Board for Human Protection at Baylor University Medical Center approved this research. Informed consent was obtained, and the subjects were paid a fee for their participation. Normal subjects and patients with CF were studied contemporaneously. Blood leukocytes or buccal cells from $\mathrm{CF}$ patients were assayed for 87 CFTR mutations (Genzyme Genetics, Framingham, Massachusetts, USA). Each patient had the approval of his or her primary care pulmonologist before engaging in these experiments. Normal volunteers were seminary students and their spouses and employees of Baylor Hospital.

Steady-state perfusion technique. Absorption and secretion were measured by intubation of the jejunum with a triple-lumen tube and constant perfusion of the jejunal lumen with isotonic test solutions. The test solutions contained a nonabsorbable volume marker, polyethylene glycol (PEG; MW 3350). Solutions were infused at a rate of $10 \mathrm{ml} / \mathrm{min}$ through the infusion aperture of the tube, the position of which was verified by fluoroscopy to be located at the ligament of Treitz. After steady-state conditions were obtained, samples of jejunal perfusate were collected at a constant rate $(1.5 \mathrm{ml} / \mathrm{min})$ for 1 hour from apertures in the tube located 10 and $40 \mathrm{~cm}$ distal to the infusion aperture. Using previously reported analytical methods and standard nonabsorbable marker equations, solute and water absorption rates by the $30-\mathrm{cm}$ segment of proximal jejunum (located between the two sampling sites) were measured $(16,17)$.

Potential difference. Potential difference (PD) was continuously recorded between a flowing intraluminal electrode and a subcutaneous reference electrode (18). The reference electrode consisted of saline in a Kendall Medicut IV Cannula (Tyco Healthcare UK Ltd., Ballymoney, United Kingdom) inserted into the subcutaneous tissue of the dorsal aspect of the forearm. This subcutaneous reference and the flowing luminal catheter were connected by $3 \mathrm{M} \mathrm{KCl}$ agar bridges and calomel half-cells to the input terminals of a batterypowered electrometer (model 610C; Keithley Instruments Inc., Cleveland, Ohio, USA), and the output was displayed on a chart recorder (Model BD 111/112; Kipp $\&$ Zonen BV, Delft, The Netherlands).

Perfused test solutions. Five separate experiments involving infusion of different test solutions were performed. All solutions contained PEG, $2 \mathrm{~g} / \mathrm{l}$, and were isotonic to plasma. The solute composition of test solutions is expressed as millimoles per liter. The balanced electrolyte solution contained $\mathrm{Na}^{+} 140, \mathrm{Cl}^{-} 92, \mathrm{HCO}_{3}{ }^{-} 45, \mathrm{~K}^{+} 4$, $\mathrm{SO}_{4}{ }^{2-} 3.5$, and mannitol 23.5. To measure gradient-generated passive chloride absorption, five different solutions were infused, each containing $\mathrm{Na}^{+} 140$ and $\mathrm{K}^{+} 4 \mathrm{Cl}^{-}$ ranged from 104 to 140 , with a reciprocal decrease in $\mathrm{SO}_{4}{ }^{2-}$ and mannitol concentrations sufficient to maintain anion/cation balance and isotonicity. The glucose$\mathrm{NaCl}$ solution contained glucose $70, \mathrm{Na}^{+} 110, \mathrm{Cl}^{-} 115$, and $\mathrm{K}^{+} 5$. The two solutions used to measure diffusion potential contained $\mathrm{Cl}^{-} 4, \mathrm{~K}^{+} 4$, mannitol 280 ; and $\mathrm{Na}^{+}$ $145, \mathrm{Cl}^{-} 4, \mathrm{~K}^{+} 4, \mathrm{SO}_{4}{ }^{2-}-72.5$, and mannitol 100 . The solution to measure the L-xylose/urea diffusion ratio was $\mathrm{Na}^{+}$ 90, $\mathrm{Cl}^{-}$90, mannitol 45, urea 39, and L-xylose 18.

Statistics. Statistical significance of differences was assessed by a $t$ test. $P$ values less than 0.05 were considered statistically significant.

Table 1

Demographics and CFTR mutation analysis

\begin{tabular}{|c|c|c|c|c|c|c|c|c|c|}
\hline Patient & Sex, age & CFTR mutation analysis & $\begin{array}{l}\text { Meconium } \\
\text { ileus }\end{array}$ & $\mathrm{BMI}^{\mathrm{A}}$ & $\begin{array}{c}\text { FVC } \\
\text { (\% pred) }\end{array}$ & $\begin{array}{c}\text { FEV }_{1} \\
\text { (\% pred) }\end{array}$ & $\begin{array}{l}\text { Work/school } \\
\text { status }^{\mathrm{B}}\end{array}$ & $\begin{array}{c}\text { Number of } \\
\text { hospital admissions }\end{array}$ & $\begin{array}{l}\text { Experiment } \\
\text { conducted }\end{array}$ \\
\hline 1 & $F, 33$ & $\Delta F 508 / 1898+1 G-A$ & No & 23 & 112 & 106 & 1 & 1 & $b, c, d, e$ \\
\hline 2 & $M, 28$ & $\Delta F 508 / \Delta F 508$ & Yes & 18 & 35 & 23 & 2 & 2 & $b, c, d, e$ \\
\hline 3 & $F, 21$ & $W 1282 X / W 1282 X$ & Yes & 22 & 77 & 76 & 1 & 1 & $a, b, d$ \\
\hline 4 & $M, 26$ & G551D/G542X & No & 23 & 68 & 65 & 1 & 1 & b \\
\hline 5 & $M, 20$ & $\Delta F 508 / \Delta F 508$ & Yes & 19 & 106 & 99 & 1 & 1 & $b$ \\
\hline 6 & M, 24 & $\Delta F 508 / \Delta F 508$ & Yes & 18 & 69 & 58 & 1 & 1 & $b$ \\
\hline 7 & $M, 34$ & $\Delta F 508 / \Delta F 508$ & No & 22 & 64 & 45 & 1 & 0 & $a, b, d$ \\
\hline 8 & $F, 20$ & $\Delta F 508 / \Delta F 508$ & No & 21 & 81 & 91 & 1 & 2 & $\mathrm{a}, \mathrm{c}, \mathrm{d}, \mathrm{e}$ \\
\hline 9 & M, 28 & $\Delta F 508 / \Delta F 508$ & No & 18 & 83 & 67 & 1 & 1 & a, d \\
\hline 10 & $F, 38$ & $\Delta F 508 / \Delta F 508$ & No & 22 & 58 & 39 & 3 & $4^{\mathrm{E}}$ & $\mathrm{a}$ \\
\hline 11 & $M, 28$ & $\Delta F 508 / \Delta F 508$ & Yes & 18 & 55 & 44 & 1 & 1 & $c, e$ \\
\hline 12 & $M, 27$ & Negative $^{\mathrm{F}} / \Delta F 508$ & No & 22 & 48 & 44 & 2 & 2 & $c, e$ \\
\hline
\end{tabular}

A Healthy adult body mass index: $18.5-24.9 \mathrm{~kg} / \mathrm{m}^{2}$. BWork/school status: 1 , full time; 2 , part time; 3 , not working or in school (patient 10 is a full-time homemaker). CNumber of hospital admissions during the calendar year in which the experiments were performed. DThe solutions used are identified by the assigned letters as follows: a, balanced electrolyte solution; b, chloride gradient studies; c, glucose- $\mathrm{NaCl}$ solution; d, diffusion potentials; and e, L-xylose/urea diffusion ratio. ESix months after our studies, patient 10 rapidly deteriorated and received a lung transplant, which is functioning well. ${ }^{\mathrm{F}} \mathrm{Negative}$ indicates that alleles test negative for

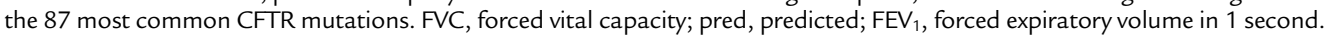




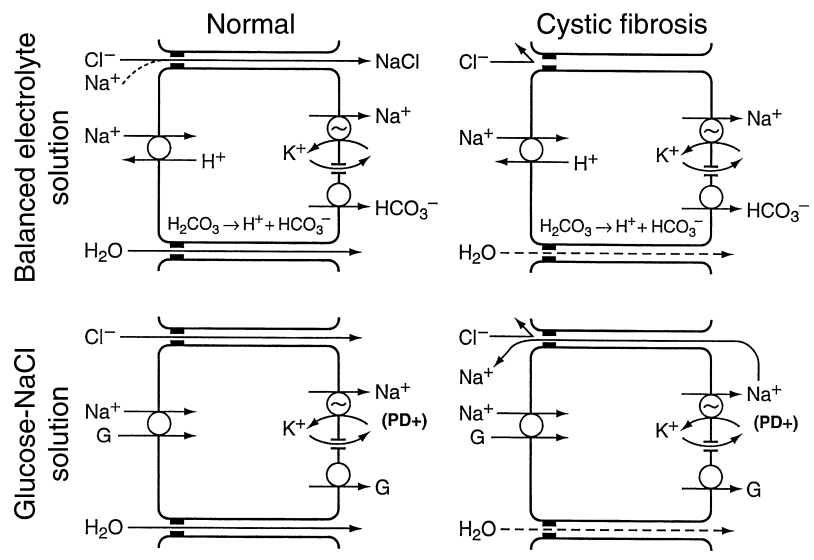

\section{Figure 1}

Conventional models of normal electrolyte absorption by the human jejunum and a possible explanation for chloride malabsorption in cystic fibrosis. The illustrations represent epithelial cells and the adjacent tight-junction paracellular pathways. The apical membrane is on the left and the basolateral membrane is on the right side of each cell. A $\mathrm{Na}^{+}, \mathrm{K}^{+}$-ATPase on the basolateral membrane pumps $\mathrm{Na}^{+}$out of the cell, into the subepithelial space. For convenience, water absorption is depicted as occurring exclusively through paracellular spaces, although it may also occur through the cell. Since these are models of electrolyte absorption, the transporters and channels that mediate active chloride secretion are not depicted. Detailed explanations of the models for normal absorption and a proposed explanation for passive chloride malabsorption in cystic fibrosis are provided within the Results and Discussion sections, respectively.

\section{Results}

Patient demographics. Eleven of the $12 \mathrm{CF}$ patients have defined mutations on both CFTR alleles (Table 1). All patients have chronic sinopulmonary infections and steatorrhea due to pancreatic insufficiency. Five of the patients had meconium ileus as newborns. Patients 4 and 6 had single episodes of possible distal intestinal obstruction syndrome, although $x$-ray studies failed to reveal an obstruction. No differences were detected between the eight patients who are homozygous for $\Delta F 508$ mutations and the four patients with other mutations, or between patients with and without a history of meconium ileus. The functional status of the patients is provided in the table. Performance of these experiments was not associated with any deleterious effects on patient health.

CF patients do not byperabsorb electrolytes and water during perfusion of a balanced electrolyte solution in vivo. The generally accepted mechanisms for jejunal absorption of a balanced electrolyte solution $(19,20)$ are summarized in the top left diagram of Figure $1 . \mathrm{Na}^{+}$is absorbed across the apical membrane in exchange for $\mathrm{H}^{+}$. The secreted $\mathrm{H}^{+}$ions react with and dissipate luminal $\mathrm{HCO}_{3}{ }^{-} \cdot \mathrm{Na}^{+}$is pumped out of the cell across the basolateral membrane, accompanied by $\mathrm{HCO}_{3}{ }^{-}$derived from intracellular $\mathrm{H}_{2} \mathrm{CO}_{3}$. This absorptive mechanism does not generate an electrical PD favoring passive chloride absorption. However, water absorption resulting from absorption of $\mathrm{NaHCO}_{3}$ causes the concentration of luminal chloride to rise, ultimately to $140 \mathrm{mEq} / \mathrm{l}$ when luminal bicarbonate is fully dissipated. In normal subjects, this chloride-concentration gradient results in passive $\mathrm{Cl}^{-}$absorption via the tight-junction paracellular pathway; this is followed by additional $\mathrm{Na}^{+}$absorption to maintain electrical balance, and this passive $\mathrm{NaCl}$ absorption promotes further water absorption. In opposition to these absorptive mechanisms, the jejunum simultaneously secretes chloride via apical membrane CFTR channels $(19,20)$. Net water movement depends upon the relative rates of electrolyte absorption versus electrolyte secretion. Since chloride secretion is reduced in CF jejunum (15), increased net absorption would be expected.

During perfusion of a balanced electrolyte solution, net absorption of sodium and water was at a low-normal level in CF patients (Figure 2), rather than high, as predicted. Lower than expected absorption by $\mathrm{CF}$ jejunum cannot be attributed to reduced $\mathrm{Na}^{+} / \mathrm{H}^{+}$ exchange because bicarbonate absorption was perfectly normal, and bicarbonate absorption is a direct measure of jejunal $\mathrm{Na}^{+} / \mathrm{H}^{+}$exchange (21). CF patients have reduced active chloride secretion (15); therefore, if they absorb chloride normally, net chloride absorption rate should be supranormal. Net chloride absorption was not increased, however, suggesting that chloride absorption is depressed in CF jejunum.

Absence of chloride absorption in response to chloride-concentration gradients. The jejunum was perfused with test solutions designed to provide a progressive increase in the chloride-concentration gradient between lumen and plasma. The absence of bicarbonate from these solutions removes a luminal buffer for secreted hydrogen ions, inhibiting $\mathrm{Na}^{+} / \mathrm{H}^{+}$exchange $(16,22)$. Furthermore, normal human jejunum does not actively absorb chloride $(17,22-24)$. Under these conditions, therefore, net chloride transport represents the balance between gradient-generated passive chloride absorption and CFTR-mediated active chloride secretion.

In normal subjects, the regression line indicated a chloride secretion rate of $7 \mathrm{mEq} / \mathrm{h} / 30 \mathrm{~cm}$ in the absence of a chloride-concentration gradient (i.e., when luminal chloride concentration was $104 \mathrm{mEq} / \mathrm{l}$ ) (Figure 3). As luminal chloride concentration was raised above the concentration of chloride in plasma, passive chloride absorption offset CFTR-mediated chloride secretion. When luminal chloride concentration exceeded 125 $\mathrm{mEq} / \mathrm{l}$, net chloride absorption was observed.

In CF patients, the regression line indicated that chloride secretion, in the absence of a chloride-concentration gradient between plasma and lumen, was lower than normal. This is consistent with reduced CFTRmediated chloride secretion (15). CF patients, however, continued to secrete chloride even with luminal chloride concentrations as high as $135-140 \mathrm{mEq} / 1$ (Figure $3)$. Therefore, passive gradient-generated chloride absorption by CF jejunum was absent.

Absence of net $\mathrm{NaCl}$ absorption by $\mathrm{CF}$ jejunum in response to $\mathrm{Na}^{+}$-glucose cotransport. As summarized in the bottom left 


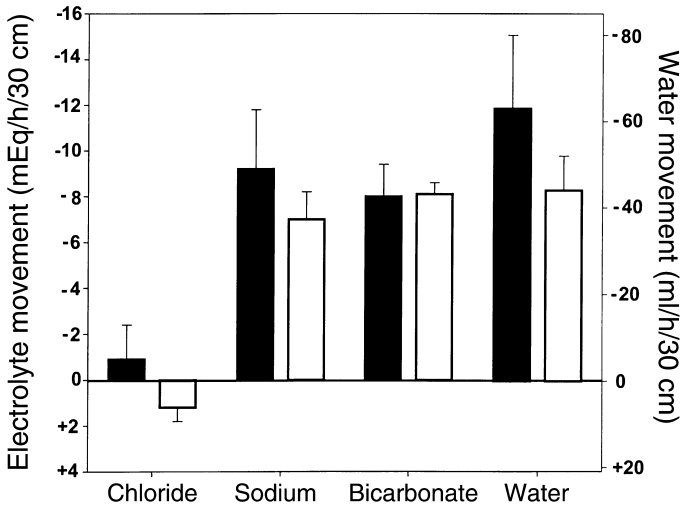

Figure 2

Net absorption and secretion during perfusion of a balanced electrolyte solution. Values are mean \pm SEM. Minus signs denote net absorption (disappearance from the lumen), and plus signs denote net secretion (gain to the lumen). Black bars denote normal control subjects, $n=5$, and white bars denote CF patients, $n=5$. There was no statistically significant difference between controls and CF patients.

diagram of Figure $1, \mathrm{Na}^{+}$-glucose cotransport causes $\mathrm{Na}^{+}$ to move across the apical membrane, from jejunal lumen into the cell, and a basolateral ATPase pump moves $\mathrm{Na}^{+}$ out of the cell into the subepithelial space. Since $\mathrm{Na}^{+}$is not accompanied across the basolateral membrane with an anion, this process generates an electrical potential difference between lumen and subepithelial space. In response to this potential, normal subjects absorb $\mathrm{Cl}^{-}$ passively via the tight-junction paracellular pathway, allowing net absorption of $\mathrm{NaCl}$. We hypothesized that CF jejunum would not absorb chloride in response to the electrical gradient generated by the $\mathrm{Na}^{+}$-glucose cotransport. To test this hypothesis, we perfused the jejunum with a glucose- $\mathrm{NaCl}$ solution. Glucose was absorbed at the same rate in normal subjects and CF patients, and PD was lumen negative in both groups (Figure 4), indicating normal electrogenic $\mathrm{Na}^{+}$-glucose cotransport by $\mathrm{CF}$ jejunum. In normal jejunum, $\mathrm{Na}^{+}$-glucose cotransport was associated with high rates of net sodium, chloride, and water absorption. In contrast, $\mathrm{Na}^{+}$-glucose cotransport in CF patients was associated with essentially zero net sodium and chloride absorption, and water absorption was only one-third as great as in normal subjects.

Diffusion potentials show reduced permeability of CF jejunum to chloride. Perfusion solutions that create ion concentration gradients across the mucosa generate PDs that reflect the relative permeability of an epithelium to different ions (25-27). Perfusing the jejunum with isotonic mannitol creates concentration gradients favoring passive diffusion of sodium and chloride from plasma to lumen $(140 \mathrm{mEq} / \mathrm{l}$ gradient for sodium and 100 $\mathrm{mEq} / \mathrm{l}$ gradient for chloride). Since the gradients were not equal, PD cannot precisely determine the relative permeability of sodium and chloride in either normal or CF subjects. Differences in PD between normal and CF subjects, however, reflect differences in the ratio of chloride-to-sodium permeability. PD was more lumen-side positive in CF patients than in normal subjects, indicating a lower $\mathrm{Cl}^{-} / \mathrm{Na}^{+}$permeability ratio in CF (Figure 5).

Perfusing the jejunum with isotonic sodium sulfate establishes gradients for sulfate diffusion from lumen to plasma (gradient $145 \mathrm{mEq} / \mathrm{l}$ ) and chloride diffusion from plasma to lumen (gradient $100 \mathrm{mEq} / \mathrm{l}$ ). PD was more lumen positive in CF patients than in normal subjects, indicating that the $\mathrm{Cl}^{-} / \mathrm{SO}_{4}{ }^{2-}$ permeability ratio is lower in CF than in normal subjects.

The ratio of $L-x y l o s e$ and urea diffusion coefficients is normal in CF jejunum. L-xylose has a molecular radius of $3.4 \AA$, and urea has a molecular radius of $2.4 \AA$. These uncharged water-soluble solutes are absorbed passively by the jejunum, presumably via tight junctions ( 28 , 29). The ratio of their diffusion coefficients is a reflection of the size of the aqueous diffusion channels through which the solutes are absorbed $(29,30)$. A ratio approaching 1.0 would indicate little discrimination between the two solutes by the diffusion channels, meaning that the size of the channels is large in relation to the size of the solutes. A ratio approaching zero would indicate a high degree of discrimination and relatively small diffusion channels. Methods for calculating the diffusion ratio of these solutes have been published previously (29). We found that the L-xylose/urea diffusion coefficient ratio was $0.30 \pm 0.03$ in normal subjects and $0.35 \pm 0.03$ in CF patients $(P=0.299)$. These results indicate that the size of the aqueous channels, through which small uncharged solutes diffuse, is similar in normal and CF jejunum.

\section{Discussion}

The human jejunum does not exhibit any evidence of active chloride absorption (17, 22-24), but it readily

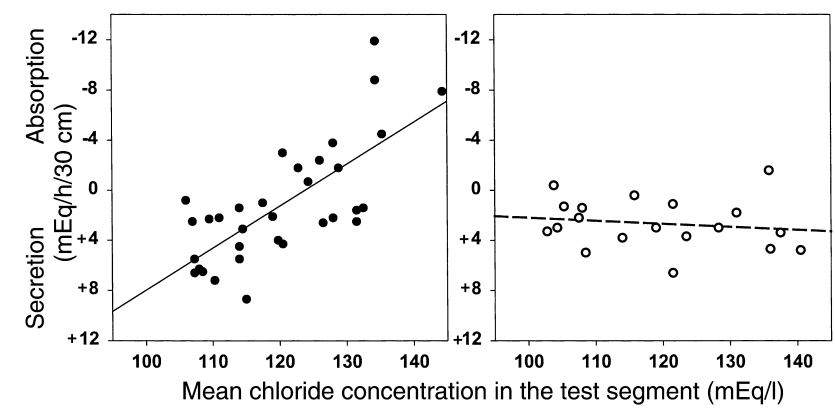

\section{Figure 3}

Net chloride absorption in response to chloride-concentration gradients. Results in normal subjects are shown on the left, and results in CF patients are shown on the right. Minus signs denote net absorption (disappearance from the lumen), and plus signs denote net secretion (gain to the lumen). Linear regression for results in normal controls, $r=0.73, P<0.001$. Linear regression for results in CF patients, $r=0.16, P=0.52$. The difference in the linear regression lines was statistically significant $(P<0.001)$. In data not shown in the figure, $\mathrm{PD}$ was lower in CF patients than in normal subjects $(-0.1 \pm 0.04 \mathrm{mV}$ versus $-1.8 \pm 0.2 \mathrm{mV}$, respectively; $P=0.02)$, in accord with reduced electrogenic chloride secretion by CF jejunum, and PD was similar at all studied levels of luminal chloride concentrations in both groups. Net sodium transport was virtually identical to net chloride transport. 


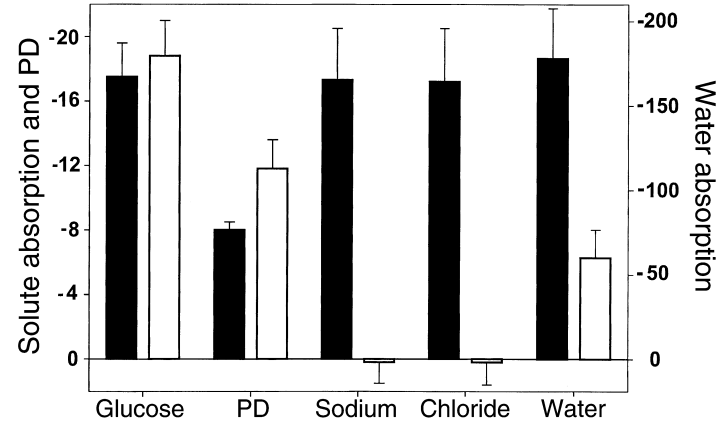

Figure 4

Net absorption and PD during perfusion of a glucose- $\mathrm{NaCl}$ solution. Black bars denote values in normal subjects, $n=5$; white bars denote values in CF patients, $n=5$. Minus signs denote net absorption of solutes and water or lumen-negative PD. Units for glucose are millimoles per hour per $30 \mathrm{~cm}$; units for PD are in millivolts; units for sodium and chloride are milliequivalents per hour per $30 \mathrm{~cm}$; and units for water are milliliters per hour per $30 \mathrm{~cm}$. $P$ values for differences between normal and $\mathrm{CF}$ are as follows: glucose, $P=0.42$; PD, $P=0.053$; sodium, $P=0.002$; chloride, $P=0.002$; water, $P=0.02$.

absorbs chloride passively in vivo in response to electrochemical gradients $(17,22)$. The jejunal capacity for passive chloride absorption in vivo is at least 16 $\mathrm{mEq} / \mathrm{h} / 30 \mathrm{~cm}$ (see Figure 4). This matches or exceeds the rate of jejunal chloride secretion in response to a prostaglandin $\mathrm{E} 1$ agonist $(16.4 \mathrm{mEq} / \mathrm{h} / 30 \mathrm{~cm})$, cholera toxin $(14.6 \mathrm{mEq} / \mathrm{h} / 30 \mathrm{~cm})$, or infection with Vibrio cholerae $(10 \mathrm{mEq} / \mathrm{h} / 30 \mathrm{~cm})(15,31,32)$. The present research has revealed a striking chloride malabsorption by the jejunum of adult patients with CF. We will discuss three possible explanations for this finding.

Defects in an undiscovered $\mathrm{Cl}^{-} / \mathrm{HCO}_{3}{ }^{-}$exchanger. If the human jejunum contained a $\mathrm{Cl}^{-} / \mathrm{HCO}_{3}{ }^{-}$exchanger, such as that in the human ileum $(19,20,33)$, a defect in this exchange could explain chloride malabsorption under some conditions (34). $\mathrm{Cl}^{-} / \mathrm{HCO}_{3}{ }^{-}$exchange in the jejunum would be electrically neutral, however, and this would not provide net transmucosal absorption of anions to balance sodium ions absorbed in response to electrogenic $\mathrm{Na}^{+}$-glucose cotransport. Therefore, even if the normal jejunum contained a previously undetected $\mathrm{Cl}^{-} / \mathrm{HCO}_{3}{ }^{-}$exchanger, a defect in this exchange could not explain absent $\mathrm{NaCl}$ absorption in $\mathrm{CF}$ patients during perfusion of a glucose- $\mathrm{NaCl}$ solution. In addition, deletion of a hypothetical $\mathrm{Cl}^{-} / \mathrm{HCO}_{3}{ }^{-}$ exchanger could not explain abnormalities in diffusion potentials that were observed in CF patients. These diffusion potential abnormalities are, however, consistent with reduced passive chloride movement through either CFTR channels or through the paracellular tight-junction pathway.

Reduced passive chloride absorption through CFTR channels. Electrochemical gradients across the apical membranes of epithelial cells determine the direction of chloride movement through CFTR channels $(19,20)$. In the intestine, these gradients are generally oriented in a secretory direction, so that chloride moves out of intes- tinal cells into the intestinal lumen. The majority of CFTR-containing cells in intestinal mucosa are located in crypts, and these cells are believed to be the main source of chloride secretion in patients with secretory diarrhea. Most epithelial cells of human jejunal villi also express CFTR, albeit in amounts much less than are present in crypts (35). In addition, a small subpopulation (less than 3\%) of jejunal villous cells express CFTR in large amounts $(35,36)$. If the electrochemical gradient across the apical membranes of CFTR-containing villous cells favored chloride absorption, these CFTR channels could mediate normal passive chloride absorption. Apical membrane CFTR channels in the eccrine sweat gland have an analogous bidirectional role, mediating chloride secretion in the secretory tubule and chloride absorption in the absorptive duct (37). If villous CFTR-containing cells did mediate passive absorption of chloride in normal subjects, then abnormal CFTR chloride channels in villous cells could explain reduced passive chloride absorption in patients with $\mathrm{CF}$. This model is attractive because a single defective molecular mechanism could then account for both reduced chloride secretion and reduced chloride absorption.

Three aspects of this hypothesis are problematic, however. First, CFTR channels mediating chloride secretion are usually closed or nearly closed in the basal state. If villous CFTR-containing cells mediated passive chloride absorption at the high rates observed in this study (Figure 4), their apical chloride channels would need to be open during perfusion of glucose solutions, and apical chloride channels of CFTR-containing cells that mediate secretion would need to be less open or closed. Second, passive chloride absorption and secretion in the normal jejunum is markedly influenced by the direction and magnitude of bulk water flow across the mucosa, even when luminal chloride concentration is constant at all levels of water

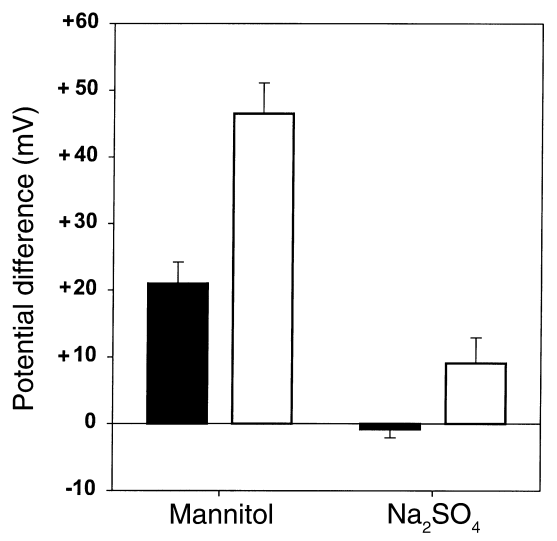

\section{Figure 5}

PD during jejunal perfusion of mannitol and sodium sulfate solutions. Minus signs denote a lumen-negative PD, plus signs denote a lumen-positive PD. Black bars denote values in normal control subjects, $n=6$; white bars denote values in CF patients, $n=6$. $P$ values for differences between normal and $\mathrm{CF}$ are as follows: mannitol, $P=0.001 ; \mathrm{Na}_{2} \mathrm{SO}_{4}, P=0.032$. 
flow (17). This solvent drag effect indicates that chloride and water traverse the mucosa through the same channels or pores. Since CFTR channels apparently do not transport water (38), it is difficult to explain the solvent drag effect if passive chloride absorption/secretion in normal jejunum occurs mainly through CFTR channels. Third, if the paracellular shunt pathway mediates a substantial fraction of passive chloride absorption, as is generally believed, a reduction in passive chloride absorption by villous CFTR cells could not explain the total absence of passive chloride absorption that we observed in CF jejunum.

Reduced passive chloride absorption through the paracellular shunt. Measurement of voltage-clamped ion fluxes and electrically equivalent circuit analysis have shown that passive sodium and chloride movement across in vitro small intestinal mucosa of laboratory animals occurs almost exclusively through leaky tight junctions in the paracellular shunt pathway (39-42). If this is also true for human jejunum in vivo, as is generally assumed (17, $19,20)$, absence of paracellular chloride absorption would reduce net electrolyte and water absorption in vivo, and the magnitude of this reduction would vary depending on the composition of intraluminal contents. As illustrated in the top right diagram of Figure 1 , during perfusion of a balanced electrolyte solution, absence of paracellular chloride absorption would block passive $\mathrm{NaCl}$ absorption in response to chloride concentration gradients and modestly reduce the rate of electrolyte and water absorption. During perfusion of a glucose-saline solution (bottom right diagram of Figure 1), absence of paracellular chloride absorption through the paracellular pathway would require $\mathrm{Na}^{+}$ ions deposited into the subepithelial space to back-diffuse into the lumen (via the tight-junction pathway) in order to maintain electrical balance. Absence of passive paracellular chloride absorption in CF patients would therefore eliminate net $\mathrm{NaCl}$ absorption in response to $\mathrm{Na}^{+}$-glucose cotransport and it would markedly reduce water absorption. The persisting water absorption would be secondary to glucose translocation from lumen to plasma, which would not be reduced by absence of passive paracellular chloride absorption.

Absence of paracellular chloride absorption might be caused by reduction in size of the tight-junction aqueous channels through which chloride is transported. The normal L-xylose/urea diffusion coefficient ratio, however, suggests that the size of this pathway is not reduced in $C F$ jejunum $(29,30)$. On the other hand, tight-junction permeability to ions might vary independent of pathway size. Experiments conducted in the 1960s (43) and 1970s $(26,44)$ indicated that control of ion permeation through the paracellular pathway is mediated by electrically charged groups within tightjunction aqueous channels. More recently, it has become apparent that several proteins, especially the family of claudin proteins, may determine ionic permeability characteristics of the tight junctions $(45,46)$. This may involve differences in electrostatic charge of the claudins and/or differences in the density of expression of unique claudins (47). Paracellular chloride absorption in the normal jejunum may depend on analogous, highly selective, tight-junction proteins.

Assuming that passive chloride absorption by the normal jejunum occurs through the paracellular shunt pathway, our finding that $\mathrm{CF}$ jejunum cannot absorb chloride suggests that CFTR regulates chloride permeability of jejunal tight junctions. This could involve a direct effect of CFTR on tight-junction proteins, or it might involve an indirect effect of CFTR mediated by cellular proteins, intracellular electrolyte concentrations or $\mathrm{pH}$, intracellular volume, etc.

Although we favor a paracellular shunt explanation of our results, caution is advised for two reasons. First, there is no absolute proof that normal human jejunum in vivo absorbs chloride passively mainly through the paracellular pathway. Second, there is no precedence for invoking CFTR regulation of paracellular permeability.

Pathophysiological implications. Regardless of the mechanism responsible for absent chloride absorption by the jejunum of CF patients, the pathophysiological consequences are profound. In CF jejunum, chloride is an unabsorbable anion, and it therefore functions as an endogenous saline cathartic to retain fluid within the lumen. This would blunt the absorption of chloride-rich fluids that are normally present within the jejunum in the fasting state. In the fed state, glucose stimulates sodium absorption via $\mathrm{Na}^{+}-$ glucose cotransport. This is the most powerful mechanism for promoting net jejunal $\mathrm{NaCl}$ and water absorption and is the physiological basis for oral rehydration of patients with cholera (48). Although CF patients absorbed glucose normally, their inability to passively absorb chloride blocked glucose-stimulated net sodium absorption and markedly reduced glucose-stimulated water absorption.

The classic intestinal ion transport defect in $\mathrm{CF}$ is the absence of active chloride secretion, which tends to dehydrate intestinal contents. The newly discovered defect in passive chloride absorption acts in physiological opposition to the classic defect. By retarding salt and water absorption, the absence of passive chloride absorption by $\mathrm{CF}$ jejunum would increase the volume of fluid delivered from the jejunum to the ileum. The ileum and colon actively absorb both sodium and chloride $(17,20,23,33,49-52)$, so reduced passive chloride absorption in the ileum and colon, if this were to occur, would not reduce net fluid absorption to the extent that it does in the jejunum. Defective CFTR-mediated chloride secretion, therefore, might result in net fluid hyperabsorption by the ileum and colon. The higher than normal volumes of fluid delivered from $\mathrm{CF}$ jejunum to CF ileum, however, would reduce the likelihood that ileal and colonic contents would become dehydrated and inspissated. In this manner, the absence of passive chloride absorption in the jejunum would tend to protect CF patients against inspissated intestinal obstruction of the ileum and colon. Since our 
studies were done in adults, we do not know if the jejunum of infants and children with $\mathrm{CF}$ also have an abnormality in passive chloride absorption.

In contrast to $\mathrm{CF}$ in humans, most mouse models of CF produce a severe intestinal phenotype with a high incidence of death due to intestinal obstruction and perforation (53). In vitro techniques have not revealed significant ion transport differences between jejunal tissue from CF mouse models and CF patients (53), but in vivo studies, comparable to those described in this paper, have apparently not been conducted in CF mouse models. Perhaps CF mouse models lack the protective effect of jejunal chloride malabsorption that we found in CF patients, either because the mouse jejunum actively absorbs chloride or because CF mice do not have a defect in passive chloride absorption. If this were the case, it could be one of the reasons why CF mice have a much greater propensity than CF patients to develop severe intestinal disease.

These results in human jejunum in vivo suggest a possible beneficial effect from absent passive paracellular chloride absorption in patients with CF. The pathophysiology of CF lung disease has been attributed in part to excessive electrogenic absorption of sodium by airway epithelium $(3,54)$, followed by passive paracellular chloride absorption $(55,56)$. If passive paracellular chloride absorption can be manipulated by altering tight-junction proteins (47), blocking passive paracellular chloride absorption by $\mathrm{CF}$ airway cells might be a useful therapeutic objective to pursue.

\section{Acknowledgments}

This work was supported by U.S. Public Health grant 5-R01-DK37172 from the National Institute of Diabetes and Digestive and Kidney Diseases and by the Southwest Digestive Disease Foundation. Shmuel Muallem, of Southwestern Medical School, provided ongoing advice and support, and his many contributions to this research are gratefully acknowledged. Mark Feldman, Robert Alpern, Walter Peterson, and Michel Baum also provided helpful advice and suggestions. Mark Millard, Claude B. Prestidge, and Alberto Torres are the primary physicians responsible for the care of many of the patients, and their cooperation is greatly appreciated.

1. Akabas, M.H. 2000. Cystic fibrosis transmembrane conductance regulator: structure and function of an epithelial chloride channel. J. Biol. Chem. 275:3729-3732.

2. Schwiebert, E.M., Benos, D.J., and Fuller, C.M. 1998. Cystic fibrosis: a multiple exocrinopathy caused by dysfunctions in a multifunctional transport protein. Am. J. Med. 104:576-590.

3. Davis, P.B., Drumm, M., and Konstan, M.W. 1996. Cystic fibrosis. Am.J. Respir. Crit. Care Med. 154:1229-1256.

4. Frase, L.L., Strickland, A.D., Kachel, G.W., and Krejs, G.J. 1985 Enhanced glucose absorption in the jejunum of patients with cystic fibrosis. Gastroenterology. 88:478-484.

5. Berschneider, H.M., et al. 1988. Altered intestinal chloride transport in cystic fibrosis. FASEB J. 2:2625-2629.

6. Baxter, P., Goldhill, J., Hardcastle, J., Hardcastle, P.T., and Taylor, C.J. 1990. Enhanced intestinal glucose and alanine transport in cystic fibrosis. Gut. 31:817-820.

7. O'Loughlin, E.V., et al. 1991. Abnormal epithelial transport in cystic fibrosis jejunum. Am. J. Physiol. 260:G758-G763.
8. Grubb, B.R. 1995. Ion transport across the jejunum in normal and cystic fibrosis mice. Am. J. Physiol. 268:G505-G513.

9. Van Doorninck, J.H., et al. 1995. A mouse model for the cystic fibrosis delta F508 mutation. EMBO J. 14:4403-4411.

10. Beesley, A.H., Hardcastle, J., Hardcastle, P.T., and Taylor, C.J. 1996. Sodium/glucose cotransporter activity in cystic fibrosis. Arch. Dis. Child. 75:170.

11. Clarke, L.L., and Harline, M.C. 1996. CFTR is required for cAMP inhibition of intestinal $\mathrm{Na}^{+}$absorption in a cystic fibrosis mouse model. Am. J. Physiol. 270:G259-G267.

12. Taylor, C.J., Baxter, P.S., Hardcastle, J., and Hardcastle, P.T. 1988. Failure to induce secretion in jejunal biopsies from children with cystic fibrosis. Gut. 29:957-962.

13. Clarke, L.L., et al. 1992. Defective epithelial chloride transport in a genetargeted mouse model of cystic fibrosis. Science. 257:1125-1128.

14. Teune, T.M., et al. 1996. In vivo measurement of chloride and water secretion in the jejunum of cystic fibrosis patients. Pediatr. Res. 40:522-527.

15. Högenauer, C., et al. 2000. Active intestinal chloride secretion in human carriers of cystic fibrosis mutations: an evaluation of the hypothesis that heterozygotes have subnormal active intestinal chloride secretion. Am. J. Hum. Genet. 67:1422-1427.

16. Davis, G.R., Santa Ana, C.A., Morawski, S., and Fordtran, J.S. 1980. Active chloride secretion in the normal human jejunum. J. Clin. Invest. 66:1326-1333.

17. Fordtran, J.S., Rector, F.C., and Carter, N.W. 1968. The mechanisms of sodium absorption in the human small intestine. J. Clin. Invest. 47:884-900.

18. Read, N.W., and Fordtran, J.S. 1979. The role of intraluminal junction potentials in the generation of the gastric potential difference in man. Gastroenterology. 76:932-938.

19. Sullivan, S.K., and Field, M. 1991. Ion transport across mammalian small intestine. In Handbook of physiology. M. Field and R.A. Frizzell, editors. American Physiological Society. Bethesda, Maryland, USA. 287-301.

20. Sellin, J.H. 2002. Intestinal electrolyte absorption and secretion. In Sleisenger and Fordtran's gastrointestinal and liver disease. 7th edition. M. Feldman, L.S. Friedman, and M.H. Sleisenger, editors. Saunders. Philadelphia, Pennsylvania, USA. 1693-1714.

21. Högenauer, C., Aichbichler, B., Santa Ana, C., Porter, J., and Fordtran, J. 2002. Effect of octreotide on fluid absorption and secretion by the normal human jejunum and ileum in vivo. Aliment. Pharmacol. Ther. 16:769-777.

22. Turnberg, L.A., Fordtran, J.S., Carter, N.W., and Rector, F.C. 1970. Mechanism of bicarbonate absorption and its relationship to sodium transport in the human jejunum. J. Clin. Invest. 49:548-556.

23. Corbett, C.L., Isaacs, P.E.T., Riley, A.K., and Turnberg, L.A. 1977. Human intestinal ion transport in vitro. Gut. 18:136-140.

24. Hubel, K.A., and Renquist, K.S. 1990. Ion transport in normal and inflamed human jejunum in vitro: changes with electrical field stimulation and theophylline. Dig. Dis. Sci. 35:815-820.

25. Fordtran, J.S., and Dietschy, J.M. 1966. Water and electrolyte movement in the intestine. Gastroenterology. 50:263-285.

26. Frizzell, R.A., and Schultz, S.G. 1972. Ionic conductance of extracellular shunt pathway in rabbit ileum: influence of shunt on transmural sodium transport and electrical potential differences. J. Gen. Physiol. 59:318-346.

27. Davis, G.R., Santa Ana, C.A., Morawski, S.G., and Fordtran, J.S. 1982. Permeability characteristics of human jejunum, ileum, proximal colon and distal colon: results of potential difference measurements and unidirectional fluxes. Gastroenterology. 83:844-850.

28. Mandel, L.J., and Curran, P.F. 1972. Response of the frog skin to steady state voltage clamping. J. Gen. Physiol. 59:503-518.

29. Fine, K.D., Santa Ana, C.A., Porter, J.L., and Fordtran, J.S. 1995. Effect of changing intestinal flow rate on a measurement of intestinal permeability. Gastroenterology. 108:983-989.

30. Fordtran, J.S., Rector, F.C., Locklear, T.W., and Ewton, M.F. 1967. Water and solute movement in the small intestine of patients with sprue. J. Clin. Invest. 46:287-298.

31. Banwell, J.G., et al. 1970. Intestinal fluid and electrolyte transport in human cholera. J. Clin. Invest. 49:183-195.

32. Petritsch, W., et al. 1992. Effect of cholera toxin on the human jejunum. Gut. 33:1174-1178.

33. Turnberg, L.A., Bieberdorf, F.A., Morawski, S.G., and Fordtran, J.S. 1970. Interrelationships of chloride, bicarbonate, sodium, and hydrogen transport in the human ileum. J. Clin. Invest. 49:557-567.

34. Bieberdorf, F.A., Gorden, P., and Fordtran, J.S. 1972. Pathogenesis of congenital alkalosis with diarrhea: implications for the physiology of normal ileal electrolyte absorption and secretion. J. Clin. Invest. 51:1958-1968.

35. Strong, T.V., Boehm, K., and Collins, F.S. 1994. Localization of cystic fibrosis transmembrane conductance regulator mRNA in the human gastrointestinal tract by in situ hybridization. J. Clin. Invest. 93:347-354. 
36. Ameen, N.A., Ardito, T., Kashgarian, M., and Marino, C.R. 1995. A unique subset of rat and human intestinal villus cells express the cystic fibrosis transmembrane conductance regulator. Gastroenterology. 108:1016-1023.

37. Quinton, P.M. 1999. The sweat gland. In Cystic fibrosis in adults. J.R Yankaskas and M.R. Knowles, editors. Lippencott-Raven Publishers. Philadelphia, Pennsylvania, USA. 419-437.

38. Schreiber, R., Pavenstädt, H., Greger, R., and Kunzelmann, K. 2000. Aquaporin 3 cloned from Xenopus laevis is regulated by cystic fibrosis transmembrane conductance regulator. FEBS Lett. 475:291-295.

39. Munck, B.G., and Schultz, S.G. 1974. Properties of the passive conductance pathway across in vitro rat jejunum. J. Membr. Biol. 16:163-174.

40. Okada, Y., Irimajiri, A., and Inouye, A. 1977. Electrical properties and active solute transport in rat small intestine. II. Conductive properties of transepithelial routes. J. Membrane Biol. 31:221-232.

41. Powell, D.W. 1981. Barrier function of epithelia. Am. J. Physiol. 241:G275-G288.

42. Armstrong, W.M. 1987. Cellular mechanisms of ion transport in the small intestine. In Physiology of the gastrointestinal tract. 2nd edition. L.R Johnson, editor. Raven Press. New York, New York, USA. 1251-1266.

43. Wright, E.M., and Diamond, J.M. 1968. Effects of $\mathrm{pH}$ and polyvalent cations on the selective permeability of gallbladder epithelium to monovalent ions. Biochim. Biophys. Acta. 163:57-74.

44. Barry, P.H., Diamond, J.M., and Wright, E.M. 1971. The mechanism of cation permeation in rabbit gallbladder: dilution potentials and biionic potentials. J. Membrane Biol. 4:358-394.

45. Goodenough, D.A. 1999. Plugging the leaks. Proc. Natl. Acad. Sci. U. S. A 96:319-321.

46. Spring, K.R. 2002. Claudins are the gatekeepers. Focus on "Claudins create charge-selective channels in the paracellular pathway between epithelial cells.” Am. J. Physiol. Cell Physiol. 283:C29-C30.

47. Colegio, O.R., Van Itallie, C.M., McCrea, H.J., Rahner, C., and Anderson,
J.M. 2002. Claudins create charge-selective channels in the paracellular pathway between epithelial cells. Am. J. Physiol. Cell Physiol. 283:C142-C147.

48. Pierce, N.F., et al. 1968. Effect of intragastric glucose-electrolyte infusion upon water and electrolyte balance in Asiatic cholera. Gastroenterology. 55:333-343.

49. Hubel, K.A., and Shirazi, S. 1982. Human ileal ion transport in vitro: changes with electrical field stimulation and tetrodotoxin. Gastroenterology. 83:63-68.

50. Davis, G.R., Morawski, S.G., Santa Ana, C.A., and Fordtran, J.S. 1983. Evaluation of chloride/bicarbonate exchange in the human colon in vivo. J. Clin. Invest. 71:201-207.

51. Hubel, K.A., Renquist, K., and Shirazi, S. 1987. Ion transport in the human cecum, transverse colon, and sigmoid colon in vitro: baseline and response to electrical stimulation of intrinsic nerves. Gastroenterology. 92:501-507.

52. Halm, D.R., and Frizzell, R.A. 1991. Ion transport across the large intestine. In Handbook of physiology. M. Field and R.A. Frizzell, editors. American Physiological Society. Bethesda, Maryland, USA. 257-273.

53. Grubb, B.R., and Boucher, R.C. 1999. Pathophysiology of gene-targeted mouse models for cystic fibrosis. Physiol. Rev. 79(Suppl.):S193-S214.

54. Boucher, R.C., Stutts, M.J., Knowles, M.R., Cantley, L., and Gatzy, J.T. 1986. $\mathrm{Na}^{+}$transport in cystic fibrosis respiratory epithelia: abnormal basal rate and response to adenylate cyclase activation. J. Clin. Invest. 78:1245-1252.

55. Stutts, M.J., and Boucher, R.C. 1999. Cystic fibrosis gene and functions of CFTR: implications of dysfunctional ion transport for pulmonary pathogenesis. In Cystic fibrosis in adults. J.R. Yankaskas and M.R. Knowles, editors. Lippencott-Raven Publishers. Philadelphia, Pennsylvania, USA. $3-25$.

56. Kunzelmann, K. 2001. CFTR: interacting with everything? News Physiol. Sci. 16:167-170 